\title{
WIKIPEDIA
}

\section{Đổi tiền tại Việt Nam, 1985}

Bách khoa toàn thư mở Wikipedia

Đổi tiền tại Việt Nam năm 1985 là đọt đổi tiền lần thứ ba sau khi chấm dứt chiến tranh năm 1975 ở Việt Nam. Đọt đổi tiền này nằm trong kế hoạch kinh tế Giá - lương - tiền để thực thi mô hình xã hội chủ nghĩa ở Việt Nam.[1]

Lần đổi tiền này gây ra hậu quả kinh tế tai hại với nạn lạm phát lên hơn 700\% năm 1986 và tiếp tục cao trong 3 năm sau đó.

\section{Mục lục}

\section{Bối cảnh \\ Thi hành \\ Mệnh giá \\ Hậu quả \\ Xem thêm \\ Tham khảo \\ Liên kết ngoài}

\section{Bối cảnh}

Tin đồn đổi tiền đã manh nha trong dân chúng khi tình hình kinh tế thập niên 1980 ngày càng khó khăn nên chính quyền cho cơ quan truyền thông phát tán và trấn an dân tình là không có kể hoạch đổi tiền. Ngày 12 tháng 9 năm 1985, trang nhất báo Tuổi Trẻ còn khẳng định "Bẻ gãy thủ đoạn tung tin đổi tiền của gian thương..." nhưng hai ngày sau, 14 tháng 9 thì có lệnh thu hồi tiền cũ và đồng loạt thay tiền mới. Lý do đưa ra là để tăng cường "lợi ích của dân lao động."[2]

\section{Thi hành}

Việc thi hành toàn diện gồm các khoản tiền trong ngân hàng và tiền lưu hành trong dân chúng. Tiền lưu hành phải nộp lại trong vòng 3-5 ngày với tỷ lệ 1 đồng mới ăn 10 đồng cũ. Ngoài ra số tiền ký thác trong các trương mục ngân hàng cũng được định giá theo một công thức căn cứ vào thời gian ký thác như sau:[3]

1. Lượng tiền gửi trước 1 tháng 3 năm 1978: 1 đồng cũ=1 đồng mới

2. Lượng tiền gửi trong thời khoản 2 tháng 3 năm 1978 đến 31 tháng 5 năm 1981: 2 đồng cũ $=1$ đồng mới

3. Lượng tiền gửi trong thời khoản 1 tháng 6 năm 1981 đến 31 tháng 12 năm 1984: 6 đồng cũ 1 đồng mới

4. Lượng tiền gửi trong thời khoản 1 tháng 1 năm 1985 đến 31 tháng 7 năm 1985: 9 đồng cũ= 1 đồng mới, và

5. Lượng tiền gửi trong thời khoản 1 tháng 8 năm 1985 đến 14 tháng 9 năm 1985 (ngày đổi 
tiền): 10 đồng cũ=1 đồng mới.

Số tiền đang lưu hành khi đổi cũng bị hạn chế theo những số lượng nhất định:

- Mỗi gia đình chỉ được đổi 20.000 đồng cũ lấy 2.000 đồng mới

- Hộ độc thân chỉ được đổi 15.000 đồng cũ lấy 1.500 đồng mới

- Hộ kinh doanh công thương nghiệp thì được đổi 50.000 đồng cũ lấy 5.000 đồng mới.

Nếu có tiền nhiều hơn mức ấn định thì người đổi vẫn phải nộp số tiền thặng dư và chỉ được nhận lại giấy biên nhận; khoản tiền quá lượng nhà nước sẽ thu cả và đợi xét lại mai sau. [4] Theo một số trường hợp người ký thác sau 30 năm đến lãnh ra thì được biết không còn tiền nữa vì lạm phát ăn mòn, coi như mất gần hết. ${ }^{[5]}$ Theo Thống đốc Ngân hàng Nhà nước Cao Sĩ Kiêm thì cho tới nay (2015) chính phủ vẫn không có phương thức nào bù đắp cho những người gửi tiền khi tuân thủ theo chỉ định lúc bấy giờ.

\section{Mệnh giá}

Ngoài việc đổi tiền cũ theo tỷ lệ tiền mới, cuộc đổi tiền năm 1985 có chủ ý thu hồi các tờ giấy bạc có mệnh giá cao: 100 đồng, 50 đồng, 30 đồng và 20 đồng ${ }^{[6]}$ mà dùng những tờ mệnh giá thấp hầu tăng mãi lực đồng tiền Việt Nam. Tuy nhiên vì đồng tiền mất giá nên sau đó nhà nước lại phải phát hành những tờ giấy bạc với mệnh giá cao hơn nữa như tờ 200 vào năm 1987; rồi tờ 500,1000 và 2000 vào năm 1989 .

\section{Hậu quả}

Việc đổi tiền với tỷ lệ mới xóa hết những gì đã tích lũy bằng tiền mặt và đặt mọi người vào một ngạch bằng nhau. Trên lý thuyết thì rõ ý bình đẳng nhưng hậu quả kinh tế thì tai hại với nạn lạm phát lên hơn 700\% năm 1986. Tình trạng lạm phát cao tiếp diễn sang đến thập niên 1990 sau đó. Với đồng tiền mất giá, dân chúng cố mua vàng tích trữ. Tiền trong ngân hàng khi rút ra thì giá trị thấp hơn ban đầu nên có những câu châm biếm: "bán trâu tậu gà".[4]

Nếu xét về mức lương tối thiểu quy định năm 1985 là 220 đồng/tháng thì ba năm sau, 1988, đã tăng lên thành 22.500/tháng[7] đồng vì đồng tiền Việt

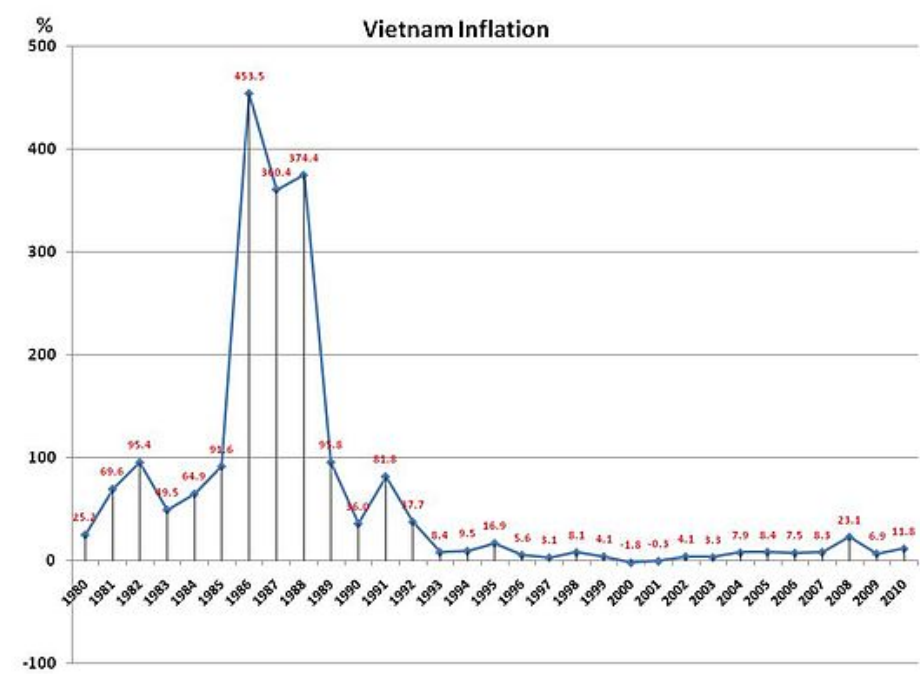

Tỷ lệ lạm phát Việt Nam giai đoạn 1980-2010. Thời điểm 1985 đánh dấu lúc lạm phát bùng nổ Nam mất giá quá nhanh.

Tuy kế hoạch đổi tiền không diễn ra như kế hoạch do sự chắp vá giữa cải cách với mô hình cũ, gây ra lạm phát nghiêm trọng, song chính điều này đã làm cho các cấp các ngành nhận ra rằng đã cải cách là phải cải cách triệt để. Đại hội Đại biểu Toàn quốc lần thứ sáu của Đảng Cộng sản Việt Nam tháng 12 năm 1986 đã đưa ra những chủ trương cải cách, đổi mới. [8]

\section{Xem thêm}


- Đổi tiền tại Việt Nam, 1975

- Đổi tiền tại Việt Nam, 1978

\section{Tham khảo}

1. ^ "Dập tắt tin đồn" (http://www.voatiengviet.com/a/viet-nam-dap-tat-tin-don-doi-tien/3620425. html)

2. ^ "Ba lần đổi tiền" (http://www.rfa.org/vietnamese/SpecialTopic/40years-april30/change-mon ey-haminhthao-04242015124546.html)

3. ^ "PHÁT HÀNH TIĖN NGÂN HÀNG MỚI, THU ĐÖI TIĖN NGÂN HÀNG CŨ" (http://thuvienp hapluat.vn/van-ban/Tien-te-Ngan-hang/Quyet-dinh-01-HDBT-TD-tien-ngan-hang-moi-thu-doi -tien-ngan-hang-cu-43628.aspx)

4. ^ $\boldsymbol{a} \boldsymbol{b}$ “"Ngẫm về những đồng xu yểu mệnh của Việt Nam" ". Bản gốc lưu trữ ngày 20 tháng 12 năm 2016. Truy cập ngày 18 tháng 12 năm 2016.

5. ^ "Tiền tiết kiệm bốc hơi..." (http://tuoitre.vn/tin/kinh-te/20141106/tien-tiet-kiem-boc-hoi-sau-3 0-nam/668059.html)

6. ^ "Giá-lương-tiền, cuộc cải cách xương máu..." (http://vnexpress.net/tin-tuc/su-kien/30-namdoi-moi/gia-luong-tien-cuoc-cai-cach-xuong-mau-truoc-doi-moi-3513420.html)

7. ^ "Lịch sử quy định lương tối thiểu..." (http://quantri.vn/dict/details/14437-lich-su-quy-dinh-ve -tien-luong-toi-thieu-o-viet-nam)

8. ^ Chính, Phạm Minh; Hoàng, Vương Quân (ngày 27 tháng 5 năm 2009). Kinh tế Việt Nam: Thăng trầm và đột phá. Nhà xuất bản Chính trị Quốc gia Sự thật.

\section{Liên kết ngoài}

Lấy từ “https://vi.wikipedia.org/w/index.php?title=Đổi_tiền_tại_Việt_Nam,_1985\&oldid=65468803"

\footnotetext{
Trang này được sửa đổi lần cuối vào ngày 14 tháng 8 năm 2021 lúc 11:41.
}

Văn bản được phát hành theo Giấy phép Creative Commons Ghi công-Chia sẻ tương tự; có thể áp dụng điều khoản bổ sung. Với việc sử dụng trang web này, bạn chấp nhận Điều khoản Sử dụng và Quy định quyền riêng tư Wikipedia® là thương hiệu đã đăng ký của Wikimedia Foundation, Inc., một tổ chức phi lợi nhuận. 